Check for updates

Cite this: Chem. Commun., 2020, 56,3039

Received 22nd November 2019, Accepted 3rd February 2020

DOI: $10.1039 / \mathrm{c} 9 \mathrm{cc} 09098 \mathrm{c}$

rsc.li/chemcomm

\section{Methylation of geometrically constrained lysine analogues by histone lysine methyltransferases $\uparrow$}

\author{
Abbas H. K. Al Temimi, (D) a Paul B. White, (D) a Marcus J. M. Mulders, ${ }^{b}$ \\ Nicole G. A. van der Linden, ${ }^{a}$ Richard H. Blaauw, ${ }^{c}$ Anita Wegert, ${ }^{\text {b }}$ \\ Floris P. J. T. Rutjes (D) *a and Jasmin Mecinović (D) *ad
}

We report synthesis and enzymatic assays on human histone lysine methyltransferase catalysed methylation of histones that possess lysine and its geometrically constrained analogues containing rigid $(E)$-alkene $\left(K_{E}\right),(Z)$-alkene $\left(K_{Z}\right)$ and alkyne $\left(K_{\text {yne }}\right)$ moieties. Methyltransferases G9a and GLP do have a capacity to catalyse methylation in the order $K>>K_{E}>K_{Z} \sim K_{y n e}$, whereas monomethyltransferase SETD8 catalyses only methylation of $K$ and $K_{E}$.

Histone lysine methylation is a universal posttranslational modification that is engaged in the regulation of many biological processes, and its dysregulation is linked to various diseases, including cancer, inflammation, and genetic disorders. ${ }^{1}$ Histone lysine methyltransferases (KMTs) in the presence of cosubstrate $S$-adenosylmethionine (SAM) catalyse methylation of lysine residues in histones and non-histone proteins via addition of one, two or three methyl groups (Kme, Kme2 and Kme3) on the $\varepsilon$-amino group of the target lysine (Fig. 1a). ${ }^{2,3}$ Demethylation of $N^{\varepsilon}$-methyllysine is catalysed by the flavin-dependent and the 2-oxoglutarate/Fe(II) dependent demethylases (KDMs), ${ }^{4}$ while different aromatic cage containing epigenetic reader proteins specifically recognise histone $N^{\varepsilon}$-methyllysine residues. ${ }^{5}$ Recent biostructural studies on ternary complexes between KMTs, histone peptides and $S$-adenosylhomocysteine ( $\mathrm{SAH}$, as a non-reactive product of the methyl transfer reaction) revealed that the SET (Su(var)3-9, enhancer-of-zeste, trithorax)

\footnotetext{
${ }^{a}$ Institute for Molecules and Materials, Radboud University, Heyendaalseweg 135, 6525 AJ Nijmegen, The Netherlands. E-mail: Floris.Rutjes@ru.nl; Tel: +31243653202

${ }^{b}$ Mercachem B.V., Kerkenbos 1013, 6546 BB Nijmegen, The Netherlands. E-mail: anita.wegert@mercachem.nl; Tel: +31243652331

${ }^{c}$ Chiralix B.V., Kerkenbos 1013, 6546 BB Nijmegen, The Netherlands

${ }^{d}$ University of Southern Denmark, Campusvej 55, 5230 Odense, Denmark. E-mail: mecinovic@sdu.dk; Tel: +4565503603

$\dagger$ Electronic supplementary information (ESI) available: Experimental and full characterization of all compounds, HPLC and MALDI analyses, supporting figures, enzyme assays, peptide synthesis, protein production, synthesis, NMR data. See DOI: 10.1039/c9cc09098c
}

a.
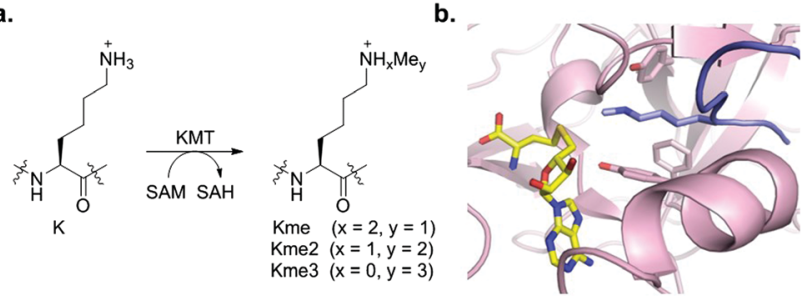

c.
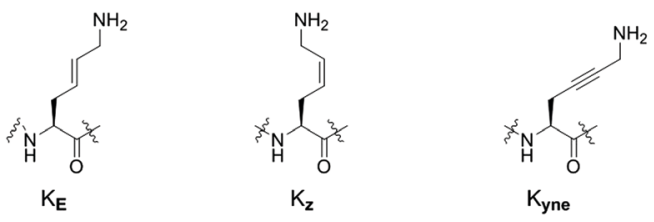

Fig. 1 (a) KMT-catalysed methylation of lysine residues in histones. (b) View from a crystal structure of GLP (magenta) in complex with H3K9me histone peptide (blue) and S-adenosylhomocysteine (SAH, yellow). (c) Geometrically constrained lysine analogues as substrates for KMTs.

domain containing KMTs have a well-defined arrangement of the binding pockets for the lysine residue and SAM, which are located at opposite sides of the SET domain and connected through a narrow hydrophobic tunnel (Fig. 1b). ${ }^{6}$ Mutation studies demonstrated that the nature of specific residues (Tyr and Phe) in the active site of the SET domain apparently determines the methylation level of particular KMTs. The Tyr $\mathrm{OH}$ group interacts with the $\varepsilon$-amine of lysine by a favourable $\mathrm{NH} \cdots \mathrm{O}$ hydrogen bond, thus orienting the amino group toward the methyl moiety of SAM for efficient methyl transfer. Kinetic studies reveled that the KMT-catalysed methyl transfer from SAM to the target lysine proceeds via an early asymmetrical $\mathrm{S}_{\mathrm{N}} 2$ transition state. ${ }^{7}$ The biocatalytic potential of KMTs has remained largely undetermined, despite significant progress in mechanistic, structural and inhibition studies on histone KMTs. ${ }^{6,8}$

Recent studies have expanded the knowledge concerning the biocatalytic activity of human KMTs via examining various lysine analogues as substrates, revealing that KMTs not only 
display a high degree of specificity towards lysine, but also to simple lysine analogues. ${ }^{9-16}$ Despite the progress in understanding of the role of the substrate-binding pocket on KMT catalysis, it is presently unclear how does the flexible lysine side chain contributes to substrate efficiency. In the ternary complex, the histone lysine side chain typically exhibits the anti (zig-zag) conformation, presumably enabling an optimal positioning towards the SAM cosubstrate for efficient methyl transfer (Fig. 1b). In this communication, we explore the importance of the conformational freedom of $\mathrm{C}-\mathrm{C}$ bonds in the lysine side chain by investigating whether KMTs do have a capacity to catalyse methylation of the simplest geometrically constrained lysine analogues incorporated in histone peptides.

We hypothesised that the conformational freedom of the lysine side chain may have a major influence on the catalytic activity of KMTs. To explore the significance of conformational restriction, we introduced different rigidifying elements at the lysine side chain having the same number of core atoms, but less conformational freedom. The three selected analogues are: (i) $\mathrm{K}_{E}$, an unsaturated lysine having an $(E)$-configured double bond between the $\gamma$ - and $\delta$-positions, ${ }^{17}$ (ii) $\mathrm{K}_{Z}$, an unsaturated lysine having a $(Z)$-configured double bond between the $\gamma$ - and $\delta$-positions, ${ }^{18,19}$ and (iii) $\mathrm{K}_{\mathrm{yne}}$, an unsaturated lysine having a triple bond between the $\gamma$ - and $\delta$-positions (Fig. 1c). ${ }^{20,21}$ Experimental details for the preparation of the three Fmoc-protected building blocks, proof of purity, and NMR data for their characterization are elaborated in the ESI. $\dagger$ The structures and syntheses of Fmoc-protected lysine analogues are shown in Scheme 1a. ${ }^{1} \mathrm{H}$ NMR and analytical SFC studies confirmed the identical structures of compound 2 obtained either via cross-metathesis or via flow hydrogenation of 3 (Fig. S5 and S6, ESI $\dagger$ ). 1D selective NOESY experiments were employed to confirm the alkene geometry of $\mathrm{K}_{Z}$ and $\mathrm{K}_{E}$ (Fig. S4, ESI $\dagger$ ).

To explore the substrate specificity of the geometrically constrained lysine analogues by human KMTs, we synthesised histone peptides corresponding to the sequence of $\mathrm{H} 3$ and $\mathrm{H} 4$ histones and subjected them to methylation by recombinantly expressed human di-/trimethyltransferases GLP and G9a, and monomethyltransferase SETD8. The chemically synthesised histone peptides are shown in Scheme 1b (H3 residues 1-15, ARTKQTARX ${ }^{9}$ STGGKA; H4 residues $13-27$, GGAKRHRX ${ }^{20}$ VLRDNIQ; Schemes S1, S2 and Fig. S7, S8, ESI $\dagger$ ). Using the three Fmoc-protected lysine analogues 1-3, we constructed six peptides substituted at the indicated position with the lysine analogue (position 9 of $\mathrm{H} 3$, position 20 of $\mathrm{H} 4$ ). All histone peptides were produced by SPPS, purified by reversed-phase HPLC, and analysed by analytical HPLC, LC-MS and MALDITOF MS (Fig. S9-S14, ESI $\dagger$ ).

To identify new substrates from these histone peptides, we first performed enzymatic assays of KMT-catalysed methylation and analysed the formation of methylated products by MALDITOF MS. Standard assays were carried out in the presence of the histone peptide $(100 \mu \mathrm{M})$, enzyme $(2 \mu \mathrm{M})$, SAM $(500 \mu \mathrm{M}$ for GLP and G9a; $200 \mu \mathrm{M}$ for SETD8) in Tris-HCl buffer at $\mathrm{pH}$ 8.0. After 1 hour incubation at $37{ }^{\circ} \mathrm{C}$, MALDI-TOF MS data showed complete trimethylation of $\mathrm{H} 3 \mathrm{~K} 9$ in the presence of GLP and G9a, and almost complete monomethylation of H4K20 in the
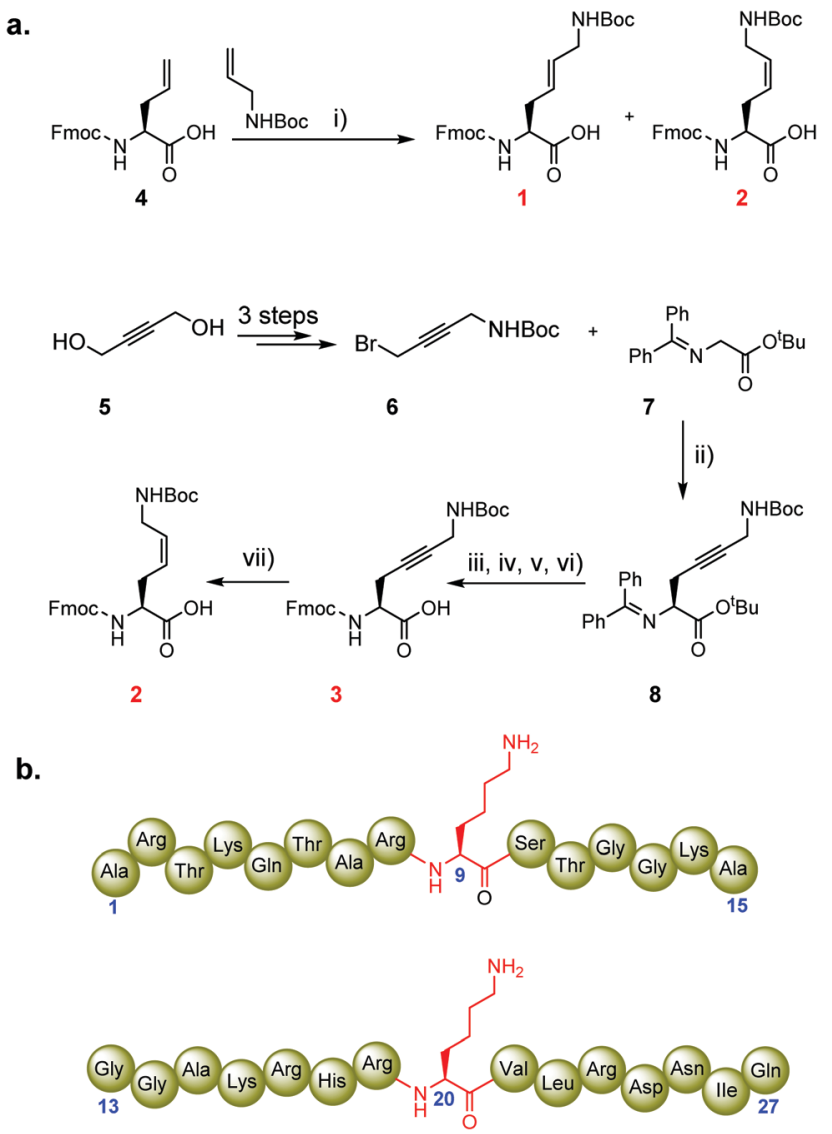

Scheme 1 Synthesis of Fmoc-protected conformationally restricted lysine analogues for Fmoc-SPPS, and sequences of synthetic histone peptides. (a) Reagents and conditions: (i) 10 mol\% $\mathrm{HGll}, \mathrm{CH}_{2} \mathrm{Cl}_{2}$, reflux, $16 \mathrm{~h}, 37 \%\left(\mathbf{1}, \mathrm{K}_{E}\right)$ and $3 \%\left(\mathbf{2}, \mathrm{K}_{Z}\right)$; (ii) $10 \mathrm{~mol} \%$ Corey's catalyst, $\mathrm{CsOH} \cdot \mathrm{H}_{2} \mathrm{O}$, $\mathrm{CH}_{2} \mathrm{Cl}_{2},-78{ }^{\circ} \mathrm{C}, 24 \mathrm{~h}, 45 \%$; (iii) citric acid (15\% aq), THF, $0{ }^{\circ} \mathrm{C} \rightarrow \mathrm{rt}, 83 \%$; (iv) Fmoc-OSu, DIPEA, $\mathrm{CH}_{2} \mathrm{Cl}_{2}, 82 \%$ : (v) TFA, $3 \mathrm{~h}$, rt; (vi) $\mathrm{Boc}_{2} \mathrm{O}$, DIPEA, $\mathrm{MeCN}, 16 \mathrm{~h}, \mathrm{rt}, 57 \%$; (vii) H-Cube hydrogenation, Lindlar catalyst, EtOAc, $10{ }^{\circ} \mathrm{C}, 38 \%\left(2, \mathrm{~K}_{\mathrm{Z}}\right)$. HGll = Hoveyda-Grubbs 2nd generation catalyst; Fmoc-OSu = Fmoc N-hydroxysuccinimide ester; DIPEA = diisopropylethylamine; $\mathrm{Boc}=$ tert-butoxycarbonyl. (b) Representative structures of histone H3K9 (1-15 aa, top) and H4K20 (13-27 aa, bottom) peptides.

presence of SETD8 (Fig. 2a, e, and Fig. S15a, ESI $\dagger$ ), in line with recent studies. ${ }^{9-13}$ Under the same conditions, the other six histone peptides containing the unsaturated $\mathrm{K}_{E}, \mathrm{~K}_{Z}$, and $\mathrm{K}_{\mathrm{yne}}$ lysine analogues were examined.

First, we investigated the activity of $\mathrm{H}_{3} \mathrm{~K}_{E} 9, \mathrm{H} 3 \mathrm{~K}_{Z} 9$, and $\mathrm{H}_{3} \mathrm{~K}_{\mathrm{yne}} 9$ with GLP and G9a. Strikingly, for both GLP and G9a we observed nearly complete trimethylation of $\mathrm{H}_{3} \mathrm{~K}_{E} 9$, producing $\mathrm{H}_{3} \mathrm{~K}_{E} 9 \mathrm{me} 3$, similar to native H3K9 (Fig. $2 \mathrm{~b}$ and Fig. S15b, ESI $\dagger$ ). $\mathrm{H}_{3} \mathrm{~K}_{Z} 9$ underwent GLP-catalysed methylation to produce mainly $\mathrm{H} 3 \mathrm{~K}_{Z} 9 \mathrm{me} 2$, while a minor amount of $\mathrm{H} 3 \mathrm{~K}_{Z} 9$ me was also observed (Fig. 2c). Similarly, G9a catalysed a predominant dimethylation of $\mathrm{H}_{3} \mathrm{~K}_{Z} 9$ (Fig. S15c, ESI $\dagger$ ). Prolonged incubation with GLP and G9a resulted in complete conversion into $\mathrm{H}_{3} \mathrm{~K}_{Z} 9 \mathrm{me} 2$ and traces of H3 $\mathrm{K}_{Z} 9 \mathrm{me} 3$ (Fig. S17, ESI $\dagger$ ). Under standard conditions, both enzymes converted $\mathrm{H} 3 \mathrm{~K}_{\mathrm{yne}} 9$ to $\mathrm{H} 3 \mathrm{~K}_{\mathrm{yne}} 9 \mathrm{me} 2$ and $\mathrm{H} 3 \mathrm{~K}_{\mathrm{yne}} 9 \mathrm{me} 3$, while only traces of $\mathrm{H}_{3 \mathrm{~K}_{\mathrm{yne}}} 9 \mathrm{me}$ were formed (Fig. $2 \mathrm{~d}$ and Fig. S15d, ESI $\dagger$ ). Prolonged incubation ( $3 \mathrm{~h})$ with GLP and 

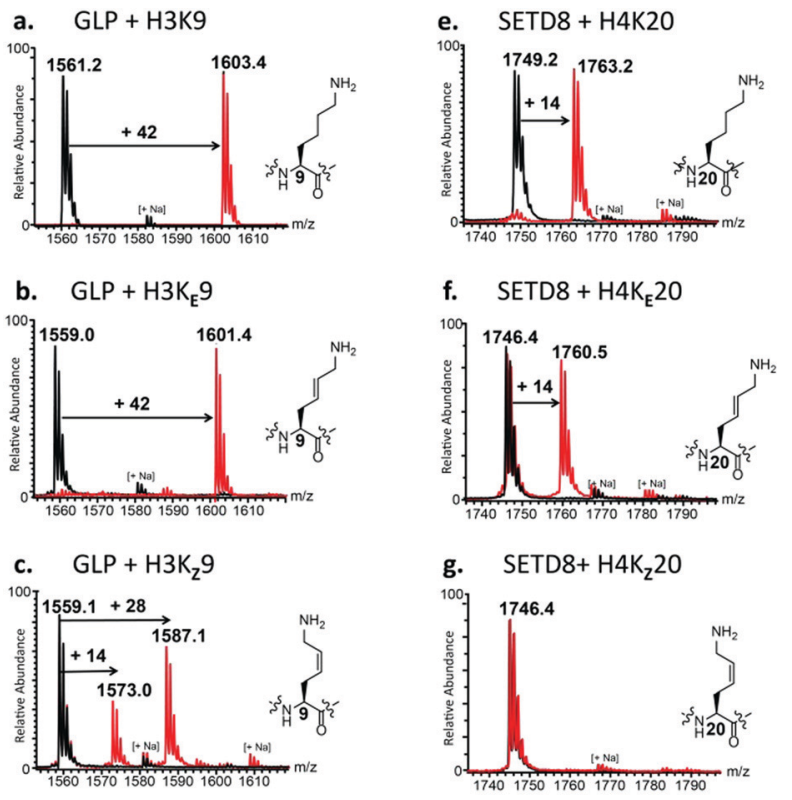

d. $\mathrm{GLP}+\mathrm{H}_{3} \mathrm{~K}_{\mathrm{yne}} 9$

${ }^{100} \mathfrak{1 5 5 7 . 2 \quad 1 5 8 5 . 2 1 5 9 9 . 3}$

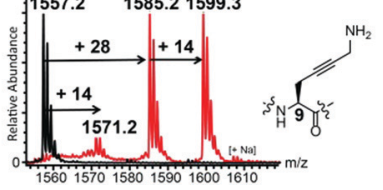

h. SETD8 $+\mathrm{H}_{4} \mathrm{~K}_{\text {yne }} 2 \mathrm{O}$

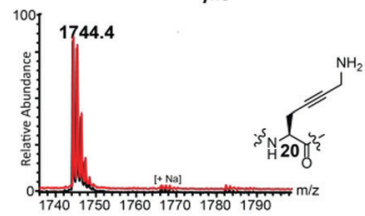

Fig. 2 KMT-catalysed methylation of lysine and its conformationally restricted analogues. MALDI-TOF MS data showing methylation of the natural and unnatural histone peptides in the presence of GLP (left panels) with (a) $\mathrm{H} 3 \mathrm{~K}$ 9, (b) $\mathrm{H}_{3} \mathrm{~K}_{E}$ 9, (c) $\mathrm{H}_{3} \mathrm{~K}_{Z}$ 9 and (d) $\mathrm{H}_{3} \mathrm{~K}_{y n e}$ 9; and SETD8 (right panels) with (e) $\mathrm{H} 4 \mathrm{~K} 2 \mathrm{O}$, (f) $\mathrm{H}_{4} \mathrm{~K}_{E} 2 \mathrm{O}$, (g) $\mathrm{H}_{4} \mathrm{~K}_{z} 2 \mathrm{O}$, and (h) $\mathrm{H}_{4} \mathrm{~K}_{\mathrm{yne}} 20$. Red spectra show reactions in the presence of KMTs, while black spectra show the no-enzyme controls.

G9a led to complete conversion into $\mathrm{H}_{3} \mathrm{~K}_{\text {yne }} 9 \mathrm{me} 3$ (Fig. S16, ESI $\dagger$ ). Control experiments in the absence of GLP/G9a with $\mathrm{H}_{3} \mathrm{~K}_{E} 9$, $\mathrm{H}_{3} \mathrm{~K}_{Z} 9$ and $\mathrm{H} 3 \mathrm{~K}_{\mathrm{yne}} 9$ substrates verified that methylation reactions are due to the KMT activity (black spectra in Fig. 2). An increased concentration of G9a/GLP $(4 \mu \mathrm{M})$ and SAM $(1 \mathrm{mM})$ led to full trimethylation of $\mathrm{H}_{3} \mathrm{~K}_{E} 9$ and $\mathrm{H}_{3} \mathrm{~K}_{\mathrm{yne}} 9$, and mono- and dimethylated forms of $\mathrm{H}_{3} \mathrm{~K}_{Z} 9$ (Fig. S18, ESI $\dagger$ ). Moreover, prolonged incubation using additional GLP $(10 \mu \mathrm{M})$ and SAM $(1 \mathrm{mM})$ led to significant amounts of $\mathrm{H}_{3} \mathrm{~K}_{Z} 9 \mathrm{me} 3$ (Fig. S19, ESI $\dagger$ ).

To further substantiate G9a/GLP-catalysed methylation of conformationally constrained lysine analogues, we carried out time course experiments (Fig. S20 and S21, ESI $\dagger$ ). As anticipated at first glance and as described above, the data confirmed that GLP and G9a efficiently catalyse methylation of the three rigidified lysine analogues with the degree of methylation progressing over time. Time course data, however, also highlighted that different methylation states of lysine analogues were produced.

Enzyme kinetic assays in the presence of G9a revealed that lysine is a superior substrate over its geometrically constrained analogues; values of enzyme catalytic efficiency $\left(k_{\text {cat }} / K_{\mathrm{M}}\right)$ showed trends $\mathrm{H} 3 \mathrm{~K} 9>>\mathrm{H}_{3} \mathrm{~K}_{E} 9>\mathrm{H}_{3} \mathrm{~K}_{Z} 9 \sim \mathrm{H} 3 \mathrm{~K}_{\mathrm{yne}} 9$ (Table 1 and Fig. S22, ESI $\dagger$ ). These differences arise from both higher $K_{\mathrm{M}}$ and lower $k_{\text {cat }}$ values. Higher $K_{\mathrm{M}}$ values might be a result of weaker
Table 1 Kinetic parameters for G9a-catalysed methylation of lysine and its geometrically constrained analogues

\begin{tabular}{llccc}
\hline Entry & H3 peptide & $K_{\mathrm{M}}(\mu \mathrm{M})$ & $k_{\text {cat }}\left(\mathrm{min}^{-1}\right)$ & $\begin{array}{l}k_{\text {cat }} / K_{\mathrm{M}} \\
\left(\mathrm{mM}^{-1} \mathrm{~min}^{-1}\right)\end{array}$ \\
\hline 1 & H3K9 & $3.45 \pm 0.6$ & $20.7 \pm 0.03$ & 6012 \\
2 & H3K $_{E} 9$ & $40.3 \pm 7.3$ & $13.0 \pm 0.11$ & 323 \\
3 & H3K $_{Z} 9$ & $103 \pm 48$ & $4.39 \pm 0.2$ & 42.8 \\
4 & H3K $_{\text {yne }} 9$ & $158 \pm 46$ & $8.01 \pm 0.22$ & 50.6 \\
\hline
\end{tabular}

binding that is possibly caused by a sterical clash between the geometrically constrained lysine analogue and the narrow lysine binding tunnel. We attribute lower $k_{\text {cat }}$ values to slower methyl transfer that is caused by non-optimal positioning of the nucleophilic amino group towards the electrophilic methyl group of SAM. It is noteworthy that the $\mathrm{sp}^{2} / \mathrm{sp}$ hybridised carbons in $\mathrm{K}_{E}, \mathrm{~K}_{Z}$ and $\mathrm{K}_{\mathrm{yne}}$ lead to slightly shorter side chains with different spatial orientation when compared to the fully $\mathrm{sp}^{3}$ hybridised lysine side chain. It is thus very likely that the positioning of the $\varepsilon$-amino group in geometrically constrained lysine analogues does not allow the formation of the low energy collinear $\mathrm{N} \cdots \mathrm{C} \cdots \mathrm{S}$ transition state, resulting in slower methyl transfer reaction.

We were then motivated to examine the analogues $\mathrm{H}_{4} \mathrm{~K}_{E} 20$, $\mathrm{H} 4 \mathrm{~K}_{Z} 20$, and $\mathrm{H} 4 \mathrm{~K}_{\mathrm{yne}} 20$ in the presence of human monomethyltransferase SETD8. Remarkably, SETD8 catalysed the conversion $(50 \%)$ of $\mathrm{H}_{4} \mathrm{~K}_{E} 20$ to $\mathrm{H}_{4} \mathrm{~K}_{E} 20$ me (Fig. 2f). Incubating the enzymatic mixture for $3 \mathrm{~h}$ at $37{ }^{\circ} \mathrm{C}$ afforded $\mathrm{H}_{4} \mathrm{~K}_{E}$ 20me with nearly full conversion (Fig. S23, ESI $\dagger$ ). In contrast, $\mathrm{H}_{4} \mathrm{~K}_{Z} 20$ and $\mathrm{H}_{4} \mathrm{~K}_{\mathrm{yne}} 20$ were not methylated within the limits of detection under the standard conditions (Fig. $2 \mathrm{~g}$ and h). Even upon prolonged incubation with additional SETD8 $(10 \mu \mathrm{M})$ and SAM (1 $\mathrm{mM})$, methylation did not take place, indicating that SETD8 is highly specific for the trans geometrical isomer over the cis isomer (Fig. S24b and c, ESI $\dagger$ ). Using the same high concentration of SETD8, almost full monomethylation of $\mathrm{H}_{4} \mathrm{~K}_{E} 20$ was observed in $1 \mathrm{~h}$ (Fig. S24a, ESI $\dagger$ ).

Inhibition and residual activity assays monitoring KMTcatalysed methylation of the histone peptides were then carried out aimed at providing data on competitive binding of these three substrates as compared to the 14-mer H3K9 sequence to the active site of G9a/GLP. Among them, $\mathrm{H}_{3 \mathrm{~K}_{E}}$ 9 appeared the most potent competing substrate of GLP and G9a (Fig. S25, $\mathrm{ESI} \dagger)$. $\mathrm{H}_{3} \mathrm{~K}_{Z} 9$ also showed significant competition with $\mathrm{H} 3 \mathrm{~K} 9$, while $\mathrm{H} 3 \mathrm{~K}_{\mathrm{yne}} 9$ showed the lowest competition in this assay.

To further investigate the role of the rigidification of lysine side chain in GLP-catalysed methylation, we expanded our studies by carrying out ${ }^{1} \mathrm{H}$ NMR and ${ }^{1} \mathrm{H}-{ }^{13} \mathrm{C}$ HSQC measurements. To verify that H3K9 undergoes GLP-catalysed methylation, we conducted enzymatic assays of the $\mathrm{H} 3 \mathrm{~K} 9$ peptide $(400 \mu \mathrm{M})$ in the presence of GLP $(8 \mu \mathrm{M})$ and SAM $(2 \mathrm{mM})$ for $1 \mathrm{~h}$ at $37{ }^{\circ} \mathrm{C}$ in Tris- $d_{11}$ buffer at pD 8.0. GLP catalysed trimethylation of $\mathrm{H} 3 \mathrm{~K} 9$, as illustrated by the appearance of a singlet at $3.03 \mathrm{ppm}\left({ }^{13} \mathrm{C} 53.0 \mathrm{ppm}, \mathrm{NMe}_{3}\right)$ (Fig. 3a and Fig. S32a, ESI $\dagger)$ and a triplet at $2.62 \mathrm{ppm}\left({ }^{13} \mathrm{C} 28.0 \mathrm{ppm}\right.$, $\mathrm{SAH}-\mathrm{CH}_{2} \gamma$ ) due to concomitant formation of $\mathrm{SAH}$, which is produced during the KMT-catalysed methylation of lysine and its simplest mimics. ${ }^{9,22}$ Non-methylated $\mathrm{H} 3$ histone peptides were also characterised by 1D and 2D NMR analyses (Fig. S26-S31, ESI $\dagger$ ). 
a.

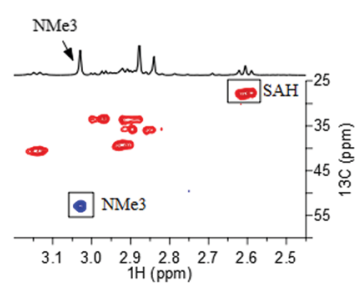

c.

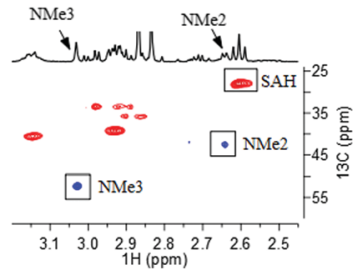

b.

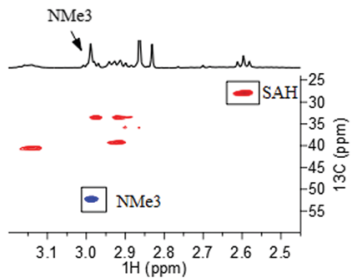

d. NMe3

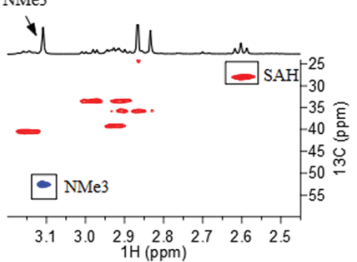

Fig. $3{ }^{1} \mathrm{H}-{ }^{13} \mathrm{C}$ HSQC data of GLP-catalysed methylation of (a) $\mathrm{H} 3 \mathrm{~K}$;

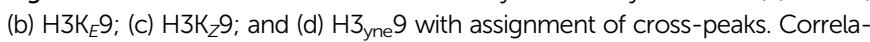
tions corresponding to the methylated lysine analogues are highlighted.

Reactions with two substrates, $\mathrm{H}_{3} \mathrm{~K}_{E} 9$ and $\mathrm{H}_{3} \mathrm{~K}_{\mathrm{yne}} 9$, showed the appearance of new singlet resonances at 2.99 and $3.11 \mathrm{ppm}$, respectively (Fig. S32b and d, ESI $\dagger$ ). Subsequent edited ${ }^{1} \mathrm{H}_{-}-{ }^{13} \mathrm{C}$ HSQC experiments revealed these signals as methyl groups with

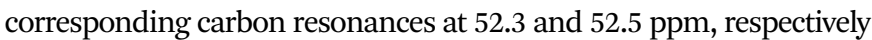
(Fig. 3b and d). The downfield chemical shift of the ${ }^{13} \mathrm{C}$ methyl groups conclusively identified these new resonances as part of an $\mathrm{NMe}_{3}{ }^{+}$moiety, indicating that the lysine analogue was trimethylated, and matched the result obtained for H3K9. Further NMR spectroscopic analysis using ${ }^{1} \mathrm{H}_{-}{ }^{13} \mathrm{C}$ HMBC and ${ }^{1} \mathrm{H}-{ }^{1} \mathrm{H}$ ROESY experiments confirmed the methylation of $\mathrm{H} 3 \mathrm{~K}_{E} 9$ and $\mathrm{H}_{3} \mathrm{~K}_{\mathrm{yne}} 9$ occurred at the 9 position due to the long-range ${ }^{1} \mathrm{H}-{ }^{13} \mathrm{C}$ coupling between the trimethylammonium group and the $\mathrm{C}_{\varepsilon}$ of the histone peptide, as well as long-range through-space interactions between the ${ }^{1} \mathrm{Hs}$ of the trimethylammonium and the ${ }^{1} \mathrm{Hs}$ of $\varepsilon-\mathrm{CH}_{2}$ (Fig. S33-S39, ESI $\dagger$ ).

$\mathrm{H}_{3} \mathrm{~K}_{Z} 9$ was unique among these analogues as two new singlet resonances appeared at 3.03 and $2.64 \mathrm{ppm}$ in the ${ }^{1} \mathrm{H}$ spectrum (Fig. 3c and Fig. S32c, ESI $\dagger$ ). The singlet at 3.03 ppm was observed to have a 1-bond ${ }^{1} \mathrm{H}_{-}{ }^{13} \mathrm{C}$ coupling to a ${ }^{13} \mathrm{C}$ resonance at $52.5 \mathrm{ppm}$, similar to both $\mathrm{H}_{3} \mathrm{~K}_{E}$ 9 and $\mathrm{H}_{3} \mathrm{~K}_{\mathrm{yne}} 9$, and was indicative of a trimethylated ammonium species, i.e. $\mathrm{H} 3 \mathrm{~K}_{Z} 9 \mathrm{me} 3$ (Fig. 3c). However, the other singlet observed at $2.64 \mathrm{ppm}$ was directly coupled to a ${ }^{13} \mathrm{C}$ resonance at $42.6 \mathrm{ppm}$. The upfield shift in both the ${ }^{1} \mathrm{H}$ and ${ }^{13} \mathrm{C}$ resonances $\left(\sim 0.5 \mathrm{ppm}\right.$ for ${ }^{1} \mathrm{H}$ and $\sim 10 \mathrm{ppm}$ for ${ }^{13} \mathrm{C}$ as compared to the other analogues) is consistent with dimethylation of $\mathrm{H}_{3} \mathrm{~K}_{Z} 9$ and literature reports of H3K9me2 and H3hK9me2. Results from GLP-catalysed methylation on $\mathrm{H}_{3} \mathrm{~K}_{Z} 9$ in the NMR assay were consistent with what was observed by MALDI-TOF MS data in the presence of increased amounts of GLP (Fig. S19, ESI $\dagger$ ).

In conclusion, our results demonstrate that human KMTs bind the histone substrate containing an $(E)$-configured dehydrolysine $\left(\mathrm{K}_{E}\right)$ in an orientation amenable for efficient methylation of the terminal $N^{\varepsilon}$-amino group. We have also shown that the corresponding $(Z)$-configured dehydrolysine $\left(\mathrm{K}_{Z}\right)$ and double unsaturated lysine ( $\mathrm{K}_{\mathrm{yne}}$ ) mimics are novel substrates for GLP and G9a, while they are not methylated by SETD8, possibly due to their improper

orientation for efficient methyl transfer. Overall, the work highlights that the conformational freedom of lysine side chain provides an important molecular and structural requirement for efficient KMT-catalysed methyl transfer reactions. We feel that these findings provide important fundamental molecular knowledge on the KMT enzyme family and may principally contribute to designing new chemical probes for KMTs.

We gratefully acknowledge financial support from the Dutch Research Council (NWO, NCI-TA grant 731.015.202) and European Research Council (ERC Starting Grant to J. M., ChemEpigen-715691). Dr Y. Vijayendar Reddy is acknowledged for fruitful discussions.

\section{Conflicts of interest}

There are no conflicts to declare.

\section{References}

1 T. Kouzarides, Cell, 2007, 128, 693-705.

2 J. C. Black, C. Van Rechem and J. R. Whetstine, Mol. Cell, 2012, 48, 491-507.

3 C. Martin and Y. Zhang, Nat. Rev. Mol. Cell Biol., 2005, 6, 838-849.

4 S. M. Kooistra and K. Helin, Nat. Rev. Mol. Cell Biol., 2012, 13, 297-311.

5 S. D. Taverna, H. Li, A. J. Ruthenburg, C. D. Allis and D. J. Patel, Nat. Struct. Mol. Biol., 2007, 14, 1025-1040.

6 M. Luo, Chem. Rev., 2018, 118, 6656-6705.

7 J. A. Linscott, K. Kapilashrami, Z. Wang, C. Senevirathne, I. R. Bothwell, G. Blum and M. Luo, Proc. Natl. Acad. Sci. U. S. A., 2016, 113, E8369-E8378.

8 M. Luo, ACS Chem. Biol., 2012, 7, 443-463.

9 A. H. K. Al Temimi, Y. V. Reddy, P. B. White, H. Guo, P. Qian and J. Mecinović, Sci. Rep., 2017, 7, 16148.

10 R. Belle, A. H. K. Al Temimi, K. Kumar, B. J. G. E. Pieters, A. Tumber, J. E. Dunford, C. Johansson, U. Oppermann, T. Brown, C. J. Schofield, R. J. Hopkinson, R. S. Paton, A. Kawamura and J. Mecinović, Chem. Commun., 2017, 53, 13264-13267.

11 A. H. K. Al Temimi, R. van der Wekken-de Bruijne, G. Proietti, H. Guo, P. Qian and J. Mecinovic, Bioconjugate Chem., 2019, 30, 1798-1804.

12 A. H. K. Al Temimi, R. S. Teeuwen, V. Tran, A. J. Altunc, D. C. Lenstra, W. Ren, P. Qian, H. Guo and J. Mecinović, Org. Biomol. Chem., 2019, 17, 5693-5697.

13 A. H. K. Al Temimi, H. I. V. Amatdjais-Groenen, Y. V. Reddy, R. H. Blaauw, H. Guo, P. Qian and J. Mecinović, Commun. Chem., 2019, 2, 112.

14 J. C. Culhane, D. Wang, P. M. Yen and P. A. Cole, J. Am. Chem. Soc., 2010, 132, 3164-3176.

15 B. C. R. Dancy, S. A. Ming, R. Papazyan, C. A. Jelinek, A. Majumdar, Y. Sun, B. M. Dancy, W. J. Drury, R. J. Cotter, S. D. Taverna and P. A. Cole, J. Am. Chem. Soc., 2012, 134, 5138-5148.

16 T. Yang, X.-M. Li, X. Bao, Y. M. E. Fung and X. D. Li, Nat. Chem. Biol., 2016, 12, 70-72.

17 G. W. Langley, A. Brinko, M. Munzel, L. J. Walport, C. J. Schofield and R. J. Hopkinson, ACS Chem. Biol., 2016, 11, 755-762.

18 E. C. Gleeson, Z. J. Wang, S. D. Robinson, S. Chhabra, C. A. MacRaild, W. R. Jackson, R. S. Norton and A. J. Robinson, Chem. Commun., 2016, 52, 4446-4449.

19 S. L. Mangold, D. J. O'Leary and R. H. Grubbs, J. Am. Chem. Soc., 2014, 136, 12469-12478.

20 G. de Bruin, E. J. van Rooden, D. Ward, C. Wesseling, A. M. C. H. van den Nieuwendijk, C. A. A. van Boeckel, C. Driessen, A. F. Kisselev, B. I. Florea, M. van der Stelt and H. S. Overkleeft, Eur. J. Org. Chem., 2017, 5921-5934.

21 E. J. Corey, F. Xu and M. C. Noe, J. Am. Chem. Soc., 1997, 119, 12414-12415.

22 F.-X. Theillet, S. Liokatis, J. O. Jost, B. Bekei, H. M. Rose, A. Binolfi, D. Schwarzer and P. Selenko, J. Am. Chem. Soc., 2012, 134, 7616-7619. 